\title{
Can immunisation trigger rheumatoid arthritis?
}

Open any rheumatology textbook and it will tell you that rheumatoid arthritis (RA) results from the interaction between a susceptible host and an unidentified environmental trigger. It seems highly unlikely, however, that all cases of RA will be attributable to a single environmental factor. It is more credible that a number of agents are capable of triggering the immunological process which is manifested clinically as RA. A rational approach to the primary prevention and treatment of the disease will be precluded until all these causes are found. It is therefore necessary to follow up all plausible aetiological clues.

One such clue is the apparent triggering of RA by immunisation. We were intrigued that, in response to a direct question, $19(3 \%)$ of the first 588 patients notified to the Norfolk Arthritis Register ${ }^{12}$ reported having a tetanus immunisation in the 6 weeks before the onset of their arthritis. Twelve of the 19 patients satisfied the 1987 ARA criteria for $\mathrm{RA}^{3}$ (table) when they were first seen, 8 were seropositive and 5 have developed radiological erosions in the first year. In addition one patient reported having an immunisation against influenza and another against hepatitis B. Neither of these patients satisfied the 1987 ACR criteria for RA. There are three possible explanations for this apparent, but uncontrolled, association between immunisation and the development of arthritis:

1 That it represents the chance occurrence of two common phenomena-namely arthritis and immunisation. A 6 week period-incidence of tetanus immunisation of $3 \%$ is equivalent to an annual immunisation rate of $28 \%$. Since tetanus immunisation need be given no more often than once every 10 years ${ }^{4}$ the maximum annual immunisation rate in adults if everyone were fully covered should not exceed $10 \%$. It is possible, however, that tetanus immunisation is a surrogate marker for some other factorsuch as trauma-which is actually the trigger for RA. Alternatively the immunisations may have been given opportunistically when the patients attended their general practitioners with prodromal features of arthritis. Further investigations are in progress to explore these possibilities. 2 That immunisation precipitates a specific form of arthritis which is distinct from RA. The tenth revision of the International Classification of Diseases ${ }^{5}$ includes, for the first time, a code $(\mathrm{M} 02 \cdot 2)$ for post-immunisation arthropathy as a sub-heading under the code for reactive arthropathy (M02). This might lead to the conclusion that post-immunisation arthropathy was a recognised disease entity but the case is far from proven.

3 That immunisation is one of the factors which can initiate RA. Infectious agents have long been the favourite candidates as potential triggers for RA. ${ }^{6}$ However, attempts to isolate organisms directly from synovium and/ or synovial fluid have, with a few exceptions, been unsuccessful. The preferred explanation is that an infection lights the blue touchpaper of the RA firework and then retires, often without trace. ${ }^{8}$ If infections can initiate RA then it is certainly plausible that immunisation, whose prime purpose is to mimic the effect of infection on the immune system, will also be capable of triggering RA.

To choose between these explanations the answers to two questions are needed. The first is whether arthritis occurs after immunisation more often than would be expected by chance. The second is whether postimmunisation arthritis is a distinct disease entity.

\section{Evidence that immunisation may precipitate arthritis \\ Case reports}

There is a substantial body of evidence, much of it anecdotal, that immunisation may precipitate arthritis in some individuals. There are case reports of arthritis occurring after tetanus, ${ }^{9}$ hepatitis $\mathrm{B}^{1011}$ and smallpox vaccinations. ${ }^{12}$ Seronegative arthritis has also been reported after the therapeutic use of vaccines, for example in the treatment of malignant pleural effusion. ${ }^{13}$ Arthritis or arthralgia occurs in $0.5 \%$ of patients with bladder cancer treated with BCG. ${ }^{14}$ The patient reported as developing arthritis after tetanus immunisation ${ }^{9}$ could be classified as having RA but in most of the other reports insufficient data are supplied.

\section{Case series}

Aho et $a l^{15}$ reported the serological changes in 245 healthy military recruits who were given tetanus, typhoid, paratyphoid, mumps, diphtheria, polio and smallpox vaccine in the second and third weeks of their service. A transient rise in rheumatoid factor (RF) titre was seen in 8 subjects and a persistent rise in 2 more. None of these recruits developed arthritis. Peeler et al ${ }^{16}$ reported on 76 laboratory workers who, over a period of 12-15 years, had been repeatedly immunised against a wide variety of infectious agents. Twelve $(16 \%)$ had developed some form of arthritis ( $1 \mathrm{RA}, 3$ gout and 8 unclassified). Twenty two $(23 \%)$ had positive latex fixation tests but none had a positive Rose-Waaler. Thus immunisation can certainly lead to $R F$ production.

In 1956 Robertson and Leonard ${ }^{17}$ reported the adverse reactions seen in about 200000 military recruits aged 18-20 who were immunised against typhoid, tetanus and smallpox. They estimated that $0.3 \%$ had adverse reactions occurring 7-10 days after inoculation, the majority of which affected the joints. Both monoarthritis and polyarthritis occurred. Some cases resembled rheumatic fever while others developed a rheumatoid-like arthritis. One man, whose mother had RA, developed severe nodular RA. It is important to remember that increasing refinements have occurred in the preparation of vaccines and the incidence of $\mathrm{RF}$ production and adverse reactions in a modern cohort might well be less.

Although such case reports and case series are suggestive of a link between immunisation and arthritis, establishing a causal association requires a comparative group who have not been immunised. There is a dearth of such epidemiological studies. A cautionary tale can be found in the introduction of swine-flu vaccine in the USA. Between 1 October and 16 December 1976, 44 million adults in the USA were immunised with swine flu vaccine. Subsequently over 100 claims were filed against the USA government for various alleged rheumatological adverse reactions including RA. Kurland et al looked at the incidence of RA in the population of Rochester, Minnesota and among army personnel in the few months before and after the immunisation programme and found them to be no different. ${ }^{18}$ Using figures from the Mayo clinic $^{19}$ they calculated that 1843 cases of RA would have been expected in the whole USA exposed population in the month after immunisation. In fact only 4 were reported to the surveillance centre.

We feel that the NOAR data are sufficiently suggestive to justify the establishment of a prospective study to 
examine the link between tetanus toxoid administration and the subsequent development of RA.

\section{Rubella vaccine and arthritis}

Rubella vaccine is the only vaccine for which there is convincing evidence to date of a link with arthritis. The virus used in current vaccines is Wistar RA $27 / 3$ rubella virus. In a Canadian trial of this vaccine arthralgia occurred in $41 \%$ of women, transient arthritis in $9 \%$ and persistent arthritis (>18 months) in 5\%. ${ }^{20}$ Joint symptoms rarely occur in men $^{21}$ but arthralgia occurs in $4 \%$ of children and arthritis in $0.3 \% .^{22} \mathrm{~A}$ recent study of mumps, measles and rubella (MMR) immunisation in children in the UK found an increased risk of new episodes of joint and limb symptoms in girls, but not in boys, compared with non-immunised children. ${ }^{23}$ In both women and children the risk of frank arthritis following rubella immunisation is less than that after natural rubella infection. ${ }^{20}{ }^{23}$ In August 1991 the Institute of Medicine in the USA released a report that examined the link between immunisation with the RA 27/3 rubella vaccine strain and arthritis. ${ }^{24}$ The committee concluded that RA $27 / 3$ causes an acute arthritis in 13-15\% of females immunised. They also felt that the evidence was consistent with a causal link between rubella immunisation and chronic arthritis but that there was insufficient evidence to estimate the incidence of this complication. They did not address the question of whether chronic rubella arthritis is distinguishable from RA.

Wild rubella virus infection is complicated by arthritis in a high proportion of adult women and, less frequently, in men. ${ }^{20}$ The arthritis most commonly affects the finger joints followed by the knees and is usually symmetrical. Although usually brief and mild, joint problems can occasionally be severe and prolonged. Parvoviruses are also capable of inducing both an acute and a chronic arthritis. ${ }^{25}$ Chronic parvovirus arthropathy may resemble RA. Some patients with early RA have serological evidence of recent parvovirus infection. ${ }^{26}$ It seems likely that rubella, parvovirus and various forms of immunisation can all precipitate an arthritis which is usually self-limiting. Some patients become chronic and are then indistinguishable from other patients with RA. It is unlikely, however, that a single pathogenetic mechanism could explain the occurrence of arthritis after a natural virus infection and after administration of an inactivated toxoid.

\section{Is post-immunisation arthritis a distinct entity?}

Whether the arthritis which follows immunisation (or indeed natural viral infection) is a distinct disease entity or a form of RA is a difficult question to answer. The problem hinges on the fact that there is no specific test for RA. Instead we have to use a set of classification criteria (table). Whilst these work well in patients with established disease ${ }^{3}$ they are less helpful in categorising patients with early disease or with the mild form of inflammatory arthritis found in a community setting. ${ }^{27}$ Patients are said to have RA if they satisfy four or more criteria. Patients with fewer than four criteria or in whom the features have been present for less than six weeks are labelled as having 'undifferentiated inflammatory polyarthritis' or 'self-limiting arthritis'. If there is an identifiable putative trigger then an alternative label of 'post-viral arthritis' or 'postimmunisation arthritis' may be used. In the present paradoxical situation we must classify the 12 NOAR patients who satisfied the ARA criteria after tetanus immunisation as having RA; and the seven who do not satisfy the criteria as having post-immunisation arthritis. The existence of a case definition for RA ensures that different investigators are studying similar patients. However, it is important to bear in mind the possibility that
The 1987 revised $R A$ criteria for $R A$ (ref 3)

\begin{tabular}{|c|c|}
\hline 1 Morning stiffness & Duration greater than one hour \\
\hline 2 Arthritis of $>3$ joint areas & $\begin{array}{l}\text { At least } 3 \text { joint areas have simultaneous soft } \\
\text { tissue swelling observed by a physician. The } 14 \\
\text { possible areas are: Right or left PIP, MCP, } \\
\text { wrist, elbow, knee, ankle, MTP joints. }\end{array}$ \\
\hline 3 Arthritis of hand joint & $\begin{array}{l}\text { At least } 1 \text { area swollen (as defined above) in } \\
\text { wrist, MCP or PIP joint }\end{array}$ \\
\hline \multicolumn{2}{|l|}{4 Symmetrical arthritis } \\
\hline \multicolumn{2}{|l|}{5 Rheumatoid nodules } \\
\hline \multicolumn{2}{|c|}{6 Serum rheumatoid factor } \\
\hline \multicolumn{2}{|c|}{7 Radiographic findings typical of RA on hand $x$ rays. } \\
\hline \multicolumn{2}{|c|}{$\begin{array}{l}\text { Rheumatoid arthritis can be diagnosed if } 4 \text { of these } 7 \text { criteria are present. } \\
\text { Criteria } 1-4 \text { must be present for at least } 6 \text { weeks. Patients with other diagnoses } \\
\text { are not excluded. }\end{array}$} \\
\hline
\end{tabular}

all these patients-whether or not they satisfy the criteria for RA - may have the same disease. We might well find that the patients with mild or self-limiting disease have much to teach us about how to extinguish the blue touchpaper of RA before the firework fully explodes.

ARC Epidemiology Research Unit,

DPM SYMMONS Manchester, UK

Addenbrookes Hospital

Cambridge, UK

K CHAKRAVARTY

1 Symmons D P M, Barrett E M, Scott D G I, Silman A J. The Norfolk Arthritis Register-a study of the incidence of rheumatoid arthritis. $\mathrm{Br} \mathcal{f}$ Rheum 1990; 29 (suppl 2): 79.

2 Chakravarty K, Symmons D P M, Barrett E M, Scott D G I. Arthritis following immunisation: a report of 21 cases. Br $\mathcal{F}$ Rheum 1992; 31 (suppl 2): 116 .

3 Arnett F C, Edworthy S M, Bloch D A, et al. The American Rheumatism Association 1987 revised criteria for the classification of rheumatoid Association 1987 revised criteria for the

4 Joint committee on vaccination and immunisation. Immunisation against infectious disease. London: HMSO, 1992.

5 Intermational statistical classification of diseases and health related problems (10th rev). Geneva: World Health Organisation, 1992

6 Venables P W. Infection and rheumatoid arthritis. Curr Opin Rheumatol 1989; 1: 15-20.

7 Harris E D. Mechanisms of disease: rheumatoid arthritis-pathophysiology and implications for therapy. $N$ Engl $\mathcal{F}$ Med $1990 ; 322: 1277-89$.

8 Wilder R L, Croffard L J. Do infectious agents cause rheumatoid arthritis? Clin Orthop 1991; 265: 36-41.

9 Jawad A S M, Scott D G I. Immunisation triggering rheumatoid arthritis? Ann Rheum Dis 1989; 48: 174.

10 Hachulla E, Houvenagal E, Mingui A, Vincent G, Laine A. Reactive arthritis after hepatitis B vaccination. F Rheumatol 1990; 17: 1250-1.

11 Rogerson S J, Nye F J. Hepatitis B vaccine associated with erythem nodosum and polyarthritis. BMF 1990; 301: 345 .

12 Holtzman C M. Postvaccination arthritis. New Engl f Med 1969; 280: 111-2.

13 Lever A M L, Forsythe J, Oxford P. Acute polyarthritis following the use of Corynebacterium parvum vaccine (Coparvax) for malignant pleura effusion. Postgrad Med F 1983; 59: 799-800.

14 Lann D L, Stogdill V D, Stogdill B J, Crispen R G. Complications of bacillus Calmette-Guérin immunotherapy in 1,278 patients with bladder cancer. F Urol 1986; 135: 272-4.

15 Aho K, Konttinen A, Rajasalmi M, Wager O. Transient appearance of rheumatoid factor in connection with prophylactic vaccinations. Acta Path Microbiol Scand 1962; 56: 478-9.

16 Peeler R N, Kadull P J, Cluff L E. Intensive immunization of man: evaluation of possible adverse consequences. Ann Intern Med 1965; 63: 44-57.

17 Robertson P W, Leonard B J. Some delayed complications of inoculation. $B M \mathcal{F}$ 1956; 2: 1029-32.

18 Kurland L T, Molgaard C A, Kurland E M, Erdtmann F J, Stebbing G $E$ T. Lack of association of swine flu vaccine and rheumatoid arthritis. Mayo Clin Proc 1984; 59: 816-21.

19 Linos A, Worthington J W, O'Fallon W M, Kurland L T. The epidemiology of rheumatoid arthritis in Rochester, Minnesota: a study of incidence, prevalence and mortality. Am $\mathcal{F}$ Epidemiol 1980; 111: 87-98.

20 Tingle A J, Allen M, Petty R E, Kettyls G D, Chantler J K. Rubellaassociated arthritis. I. Comparative study of joint manifestations associated with natural rubella infection and RA 27/3 rubella immunisation. Ann Rheum Dis 1986; 45: 110-4.

21 Preblud $\mathrm{S}$. Some current issues relating to rubella vaccine. $\mathcal{F} A M A 1985$; 254: 253-6.

22 Balfour H H, Balfour C L, Edelman C K, Rierson P A. Evaluation of Wistar RA 27/3 rubella virus vaccine in children. $A m$ f Dis Child 1976; 130: 1089-91.

23 Benjamin C M, Chew G C, Silman A J. Joint and limb symptoms in children after immunisation with measles, mumps, and rubella vaccine. $B M \mathscr{f}$ 1992; 304: 1075-8.

24 Howson $C P$, Fineburg $H$ V. Adverse events following pertussis and rubella vaccines. $\mathcal{F} A M A$ 1992; 267: 392-6.

. Ann Rev Med 1990; 41: 25-34. R K. Human parvovirus infection in early rheumatoid and inflammatory arthritis, Ann Rheum Dis 1986; 45; 832-8.

27 Dugowson C, Nelson J L, Koepsell T D. Evaluation of the 1987 revised American Rheumatism Criteria for rheumatoid arthritis in a cohort of newly diagnosed female patients. Arthritis Rheum 1990; 33: 1042-6. 